\title{
Alteraciones de la morfología dendrítica neuronal en la corteza cerebral de ratones infectados con rabia: un estudio con la técnica de Golgi
}

\author{
Orlando Torres-Fernández, Gloria E. Yepes, Javier E. Gómez \\ Laboratorio de Microscopía, Instituto Nacional de Salud, Bogotá, D.C., Colombia
}

Introducción. Los signos neurológicos de la rabia son impresionantes; no obstante, el cerebro infectado sufre apenas cambios histológicos muy sutiles.

Objetivo. Estudiar la morfología neuronal mediante la técnica de Golgi, en la corteza cerebral de ratones infectados con el virus de la rabia.

Materiales y métodos. Se inocularon ratones con virus silvestre de la rabia (virus 'calle') de origen canino o con virus adaptado (virus 'fijo') de la cepa CVS (challenge virus standard). Los animales se sacrificaron en la fase terminal de la enfermedad y se fijaron por perfusión con paraformaldehído. Los cerebros se procesaron con la técnica de Golgi, se obtuvieron cortes coronales de la corteza, se contaron las neuronas impregnadas en un área de $1 \mathrm{~mm}^{2}$, se midió el tamaño de sus cuerpos celulares y se tomaron fotografías en diferentes planos de profundidad.

Resultados. Se observaron alteraciones morfológicas notables en el soma y las dendritas de neuronas piramidales, con pérdida acentuada de espinas, en 12,9\% de neuronas corticales de animales infectados con virus 'calle' por vía intracerebral; en $8,2 \%$ de neuronas de ratones inoculados con este mismo virus por la ruta intramuscular y en $31,8 \%$ de neuronas en los animales inoculados con virus 'fijo' por vía intramuscular. Además, en las muestras de material infectado el número de neuronas impregnadas por la técnica de Golgi fue considerablemente menor al observado en las muestras no infectadas.

Conclusiones. Estos resultados son evidencia de que el virus de la rabia sí puede inducir daño neuronal estructural. Además, esta infección aparentemente interfiere con los mecanismos de impregnación argéntica del método de Golgi.

Palabras clave: rabia, virus de la rabia, corteza cerebral, neuronas, neuroanatomía, técnicas histológicas.

\section{Neuronal dentritic morphology alterations in the cerebral cortex of rabies-infected mice: a Golgi study}

Introduction. The neurological signs of rabies are very dramatic. Nevertheless, the infected brain manifests only very subtle histological changes.

Objective. The neuronal morphology in the cerebral cortex of rabies-infected mice was examined by means the Golgi technique for detection of neuropathy.

Materials and methods. Two groups of mice were inoculated with rabies-one with street virus isolated from an infected dog and the second with fixed CVS (challenge virus standard) virus. At the terminal phase of illness, the animals were sacrificed and fixed for histological staining by perfusion with paraformaldehyde. Next, the brains were treated by the Golgi technique and coronal sections were obtained. Neurons enclosed within $1 \mathrm{~mm}^{2}$ frames of the frontal cortex sections were counted and the sizes of the cellular bodies were measured. Photographs of several depth levels from the sections were obtained.

Results. Cortical pyramidal neurons showed distinctive morphological alterations in the soma and dendrites (including loss of dendritic spines) in 12.9\% of cells from intracerebral infectedmice with street virus; in $8.2 \%$ of neurons from intramuscular infected-mice with street virus, and in $31.8 \%$ of neurons from mice injected intramusculary with fixed virus. In addition, the number 
of neurons impregnated by the Golgi technique in infected brains was considerably lower than in the non-infected samples.

Conclusions. Rabies virus can induce structural neuron damage. The infection also appears to induce tissue changes that interfere with the chemical mechanisms of the Golgi silver impregnation method.

Key words: rabies, rabies virus, cerebral cortex, neurons, neuroanatomy, histological techniques.

La rabia es una enfermedad neurológica mortal que presenta un cuadro clínico impresionante. Paradójicamente, el tejido cerebral infectado con el virus de la rabia no sufre alteraciones morfológicas notables (1-3); por eso se considera que la letalidad de la rabia se debe más a cambios bioquímicos y funcionales que a daño neuronal estructural $(3,4)$. No obstante, poco se conoce sobre el efecto de esta infección en el patrón dendrítico aunque el virus infecta primordialmente a las neuronas (2). En algunas enfermedades neurológicas se ha observado patología dendrítica pronunciada aunque no se detecten cambios histológicos con los métodos convencionales, es decir, aquéllos que permiten visualizar sólo un plano de corte (perfil) de la neurona $(5,6)$.

Es importante analizar el árbol dendrítico por cuanto representa el $75 \%$ del volumen de una neurona y el $90 \%$ de su superficie; esto lo convierte en el principal blanco de los impulsos excitadores e inhibitorios (6). La técnica de impregnación argéntica de Golgi es uno de los métodos que mejor describe la morfología neuronal completa en tres dimensiones (5-12). Se caracteriza porque revela sólo una pequeña proporción de células a través del tejido circundante no impregnado; es como si se llevara a cabo una disección neuronal in situ (13). El hecho de que pocas neuronas se impregnen (tomen la coloración negra) dificulta la realización de estudios cuantitativos (8), pero facilita la descripción de su morfología completa. Si la mayoría de neuronas se impregnara la superposición de los procesos celulares formaría una maraña indescifrable. Según las condiciones

Correspondencia:

Orlando Torres-Fernández, Laboratorio de Microscopía, Instituto Nacional de Salud, Avenida Calle 26 No. 51-20 otorresf@ins.gov.co

Recibido: 24/04/07; aceptado: 02/08/07 experimentales y la variante de la técnica de Golgi ensayada, el número de neuronas coloreado adecuadamente oscila entre 1 y $5 \%$ (7).

Este método se ha utilizado en neurohistología básica desde finales del siglo XIX, sin embargo, su aplicación en neuropatología ha sido relativamente escasa $(5,6)$. La única referencia hallada sobre su uso para el estudio de la patología de la rabia fue publicada por Golgi en 1894 (14). El científico italiano quería demostrar la utilidad de su método no sólo para estudiar la organización normal del sistema nervioso, sino también para la neuropatología, pues permitía "observar cambios histopatológicos no apreciables por las otras técnicas".

El propósito del presente trabajo fue estudiar la morfología neuronal, especialmente el patrón dendrítico, mediante la técnica de Golgi, en la corteza cerebral de ratones infectados con el virus de la rabia durante la fase terminal de la enfermedad.

\section{Materiales y métodos}

Se utilizaron dos tipos de inóculos virales suministrados por el Laboratorio de Virología del Instituto Nacional de Salud (INS): virus 'calle' (virus silvestre) de origen canino de circulación en territorio colombiano (15) y virus CVS, el virus 'fijo' (adaptado en laboratorio) más utilizado en experimentación.

Para aumentar la cantidad de material infectado de cada uno de los inóculos, éstos se inyectaron por vía intracerebral en ratones lactantes; los cerebros de estos animales se extrajeron, se maceraron y cada macerado se diluyó en una proporción 1:10, en una solución compuesta por agua destilada, suero equino al $2 \%$ y antibióticos. Luego se centrifugó el material y el sobrenadante se distribuyó en alícuotas preservadas a $-70^{\circ} \mathrm{C}$ (16). Los virus fueron titulados por inoculación 
intracerebral de diluciones seriadas en ratones $\left(\mathrm{DL}_{50}=10^{4}\right.$ para el virus 'fijo' CVS y $\mathrm{DL}_{50}=10^{6.6}$ para el virus 'calle').

Para el desarrollo de los ensayos experimentales se utilizaron ratones hembras ICR de cuatro semanas de edad. Los animales se inocularon con virus 'calle' por vía intracerebral o intramuscular y con virus 'fijo' por vía intramuscular. Las inoculaciones intramusculares se llevaron a cabo en una de las extremidades posteriores. Para todos los experimentos a cada animal se le inyectó $0,03 \mathrm{ml}$ de una de las alícuotas con diluciones virales $1 / 10$, equivalente a $1000 \mathrm{DL}_{50}$ para el virus 'fijo' y $100.000 \mathrm{DL}_{50}$ para el virus 'calle'. Los controles se inocularon con la solución diluyente preparada sin el virus.

Cuando los animales alcanzaron la fase terminal de la enfermedad ( 7 a 8 días después de la inoculación para el virus 'fijo' y 10 a 14 días para el virus 'calle') se anestesiaron y luego se fijaron por perfusión intracardiaca con paraformaldehído al 4\%. El mismo procedimiento de fijación se siguió con animales controles de la misma edad.

En total se utilizaron 40 animales para el estudio; 20 de ellos se inocularon con virus 'calle', 10 por vía intramuscular y 10 por vía intracerebral. Otros 10 se inocularon con virus 'fijo' por vía intramuscular. Los 10 animales restantes se dejaron como controles. Se trabajó con animales en estado terminal debido a que es en esta condición en la que se aseguran los mayores cambios en la patología cerebral de la rabia (4).

Más detalles sobre los procedimientos de inoculación y manejo de los animales se publicaron anteriormente $(16,17)$ y fueron avalados por el Comité de Ética del Instituto Nacional de Salud.

Los cerebros se extrajeron después de la perfusión y con una muestra de tejido se comprobó la presencia del virus de la rabia en la corteza mediante una técnica inmunohistoquímica $(16,18)$. Luego se procesaron por el método de GolgiColonnier según el protocolo utilizado por Fairén et al. $(9,19)$ como se resume a continuación.

Se cortaron en rodajas de 3 a $5 \mathrm{~mm}$ de espesor en un plano frontal (coronal), a nivel de la corteza motora primaria, el cuerpo calloso, el estriado y la comisura anterior $(11,16)$. Éstas se sumergieron en una solución de bicromato de potasio al $2 \%$ y glutaraldehído al $5 \%$ durante 5 días; luego se pasaron a una solución de bicromato de potasio al 3,5\% por 24 horas. Terminada la induración las muestras se transfirieron a una solución de nitrato de plata $0,75 \%$ donde permanecieron por 24 horas. Se realizó un segundo ciclo de induración en bicromato de potasio al $3,5 \%$ durante 2 a 3 días y se complementó con otro tratamiento en nitrato de plata $0,75 \%$ por 24 horas. Luego se colocaron los bloques de tejido en un vibrátomo para obtener cortes de $150 \mu \mathrm{m}$ de espesor. Éstos se deshidrataron y se montaron con bálsamo de Canadá (Sigma) sobre láminas portaobjetos sin cubrir con laminilla.

De cada uno de los cerebros se obtuvieron 10 cortes y se contaron las neuronas completas impregnadas en un área de $1 \mathrm{~mm}^{2}$ de corteza frontal que incluía todo el espesor de la misma. Se tomaron fotografías de las neuronas en diferentes planos de profundidad y con un programa de análisis de imágenes (Zeiss KS-300) se calculó el área del soma en neuronas piramidales de la capa $\mathrm{V} ; 50$ de ellas localizadas en cortes de muestras normales y 50 seleccionadas entre las más afectadas morfológicamente de las diferentes muestras infectadas.

El daño morfológico se consideró como el conjunto de alteraciones que sufre el patrón citoarquitectónico básico, en este caso, de las neuronas piramidales. La primera de ellas es la disminución en el tamaño del soma y las demás corresponden a lo que se conoce como patología dendrítica, a saber: disminución o aumento en el grosor y longitud de las dendritas, cambios en el patrón de ramificación o arborización dendrítica así como pérdida de ramificaciones y de espinas dendríticas $(5,6)$. Para la ubicación de las neuronas dentro de las capas corticales se empleó como guía el atlas de Valverde (11).

\section{Resultados}

La técnica de Golgi-Colonnier produjo excelentes imágenes especialmente de las neuronas piramidales corticales (figura $1 \mathrm{~A}$ y $\mathrm{B}$ ). La visualización de las espinas dendríticas en estas mismas neuronas es una prueba de la calidad de 


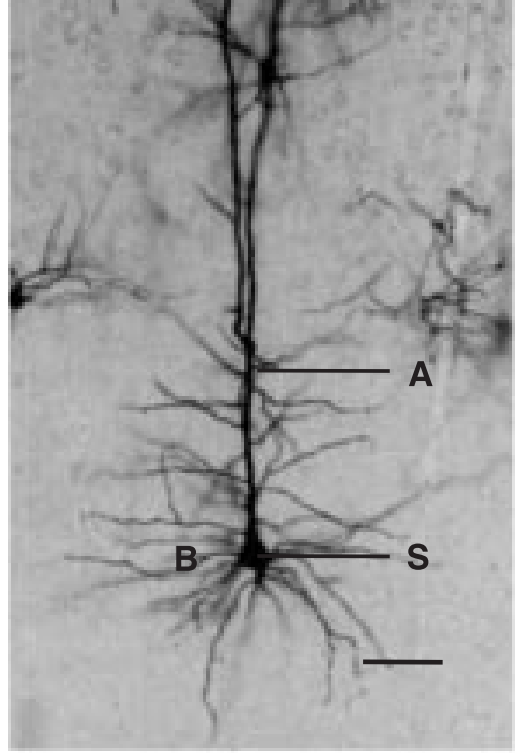

A

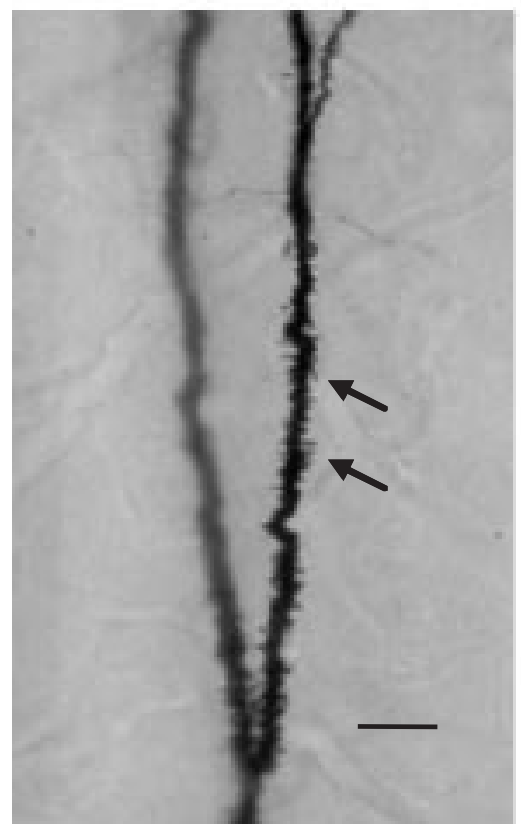

C

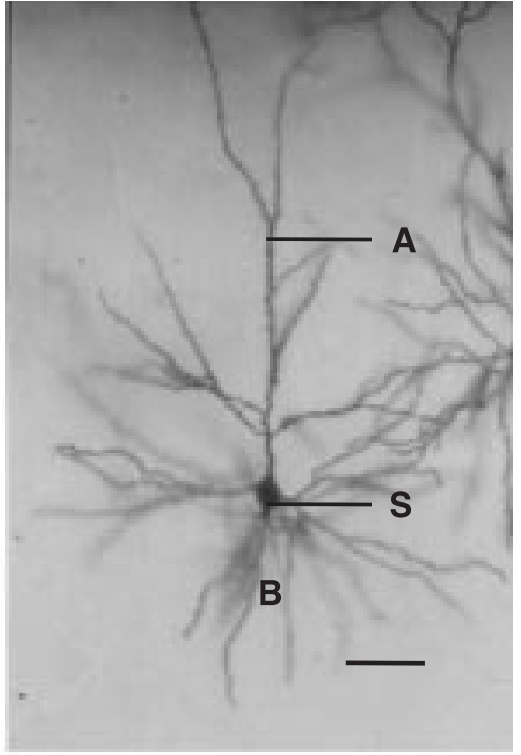

$\mathbf{B}$

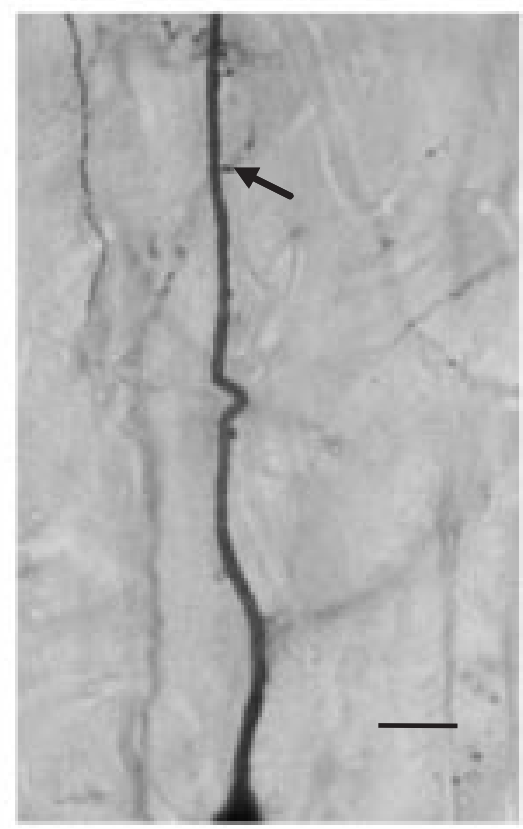

D

Figura 1. A-C. Imágenes de neuronas piramidales de la corteza cerebral de ratón normal. A. Célula piramidal de la capa V. Proliferan las dendritas basales y la dendrita apical bifurcada se dirige hacia la superficie de la corteza. La dendrita apical y su orientación es el rasgo morfológico que distingue a las neuronas piramidales corticales. Barra: $80 \mu$ m. B. Célula piramidal de la capa III. Esta neurona se observa con menor intensidad de coloración debido a que se localizaba a mayor profundidad dentro del corte. Barra: $50 \mu \mathrm{m}$. C. Detalle de la bifurcación de una dendrita apical normal. Nótense las espinas dendríticas abundantes (flechas). Barra: $25 \mu \mathrm{m}$. D. Dendrita apical de una neurona piramidal de la capa $\mathrm{V}$ cortical en un ratón inoculado con virus 'calle' de la rabia por vía intracerebral. Se observan escasas espinas (flecha). Barra: $20 \mu \mathrm{m}$. Técnica de GolgiColonnier. A: dendrita apical; B: dendritas basales; S: soma. 


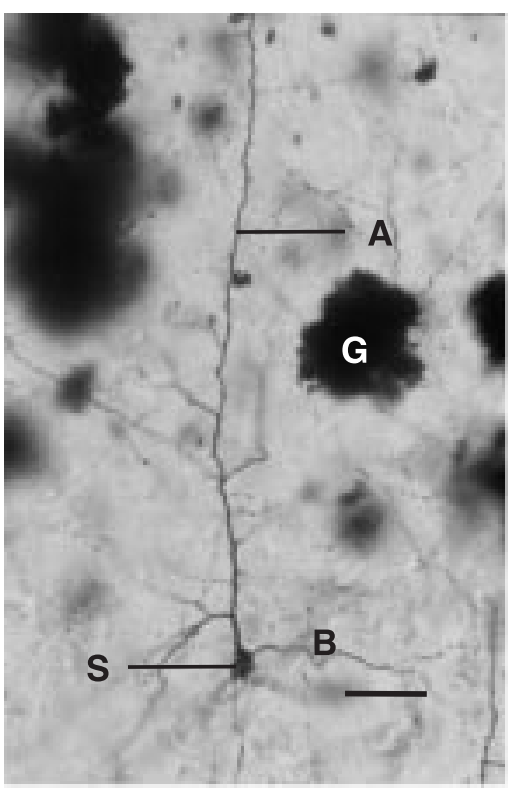

A

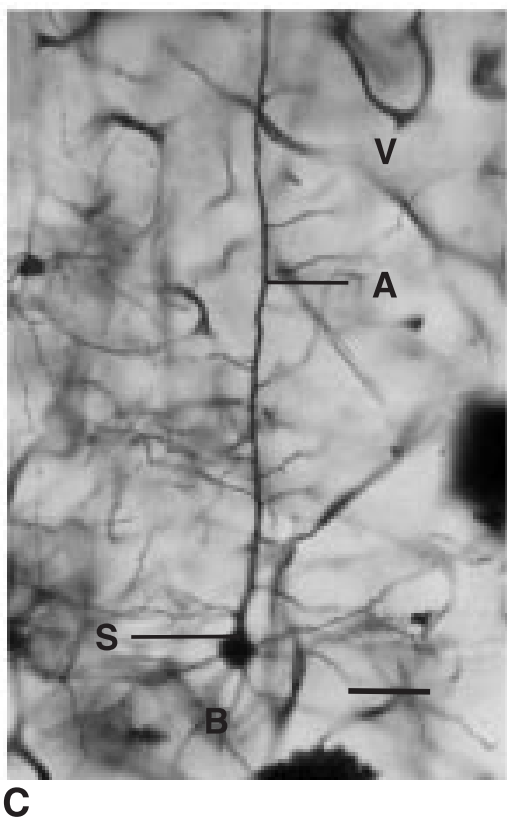

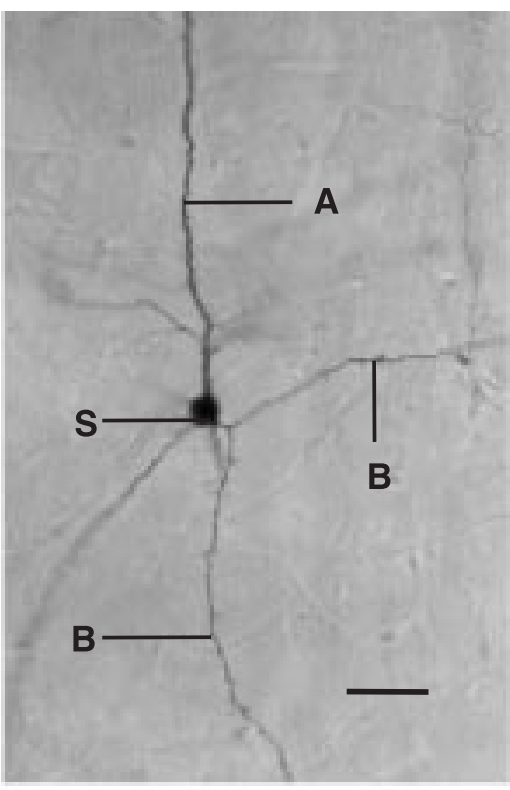

B

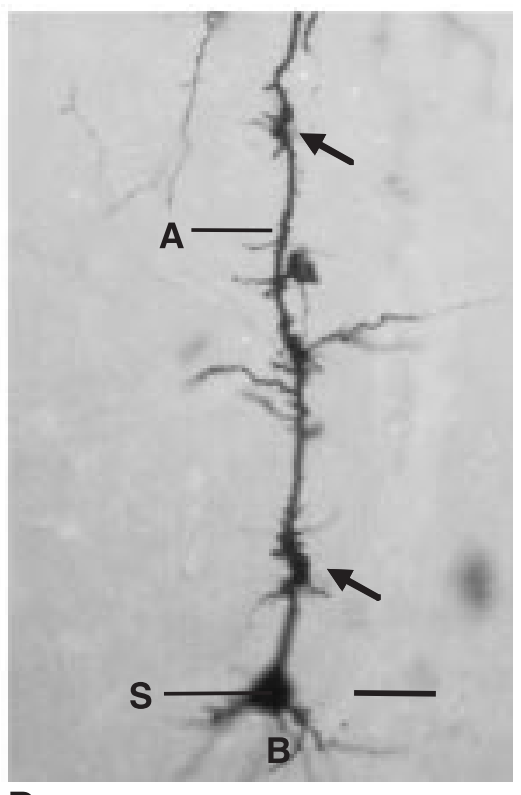

Figura 2. Neuronas piramidales de la corteza cerebral de ratones infectados con rabia. A. Célula piramidal de la capa $V$ cortical de un ratón inoculado con virus 'calle' por vía intramuscular. Se ha reducido el tamaño del cuerpo celular y las dendritas, además de ser más escasas, se han adelgazado notoriamente. Barra: $40 \mu \mathrm{m}$. B. Neurona piramidal de la capa III en un ratón inoculado con virus 'calle' por vía intracerebral. El tamaño del soma se ha reducido y las pocas dendritas basales que se conservan son anormalmente largas. Barra: $35 \mu \mathrm{m}$. C. Célula piramidal de la capa $V$ de un ratón inoculado con virus 'fijo' por vía intramuscular. Se aprecian cambios moderados en la citoarquitectura de la neurona y vasos impregnados que interfieren con la observación de los detalles de la morfología neuronal. Barra: $40 \mu \mathrm{m}$. D. Neurona piramidal de la capa $V$ de la corteza de un ratón inoculado con virus 'fijo' por vía intramuscular. La dendrita apical es tortuosa, presenta engrosamientos anormales (flechas), fragmentos de dendritas y algunas prolongaciones cortas filamentosas (filopodios). Barra: $40 \mu \mathrm{m}$. Técnica de Golgi-Colonnier. A: dendrita apical; B: dendrita basal; S: soma; G: glía; V: vasos capilares. 
la impregnación (figura 1C). La coloración original (neuronas negras sobre un fondo amarillo) de las imágenes reveladas por la técnica de Golgi se puede apreciar en un artículo anterior (12).

En las muestras correspondientes a material infectado con virus de la rabia se presentó reducción del tamaño del cuerpo neuronal, alteración del patrón de la arborización dendrítica y disminución de sus ramificaciones, adelgazamiento de las dendritas y pérdida de espinas (figuras 1D y 2 A-D). La patología dendrítica inducida por los dos tipos de virus fue similar aunque en el material inoculado con virus 'fijo' se observaron, además, neuronas con la dendrita apical tortuosa y provista de nódulos y filopodios (figura 2D). La infección con virus 'fijo' también dio lugar a la impregnación de vasos y células gliales que con frecuencia interferían con la observación de las neuronas (figura 2C).

En las muestras infectadas, además de las células con morfología normal y las que sufrieron alteraciones más evidentes se observaron otras con cambios moderados. Éstas conservaban características normales en el tamaño del soma y la citoarquitectura básica pero presentaban menos ramificaciones dendríticas y pérdida parcial de espinas (figura 2C).
En general, en todas las muestras de material infectado los cambios fueron más evidentes en las células piramidales de la capa V. El área promedio del soma de estas neuronas fue de $240 \pm 55 \mu \mathrm{m}^{2}$ en los controles $(n=50)$ mientras que en las neuronas de muestras infectadas que exhibieron atrofia fue de $192 \pm 42 \mu \mathrm{m}^{2}(\mathrm{n}=50)$; por lo tanto, hubo una disminución promedio del $20 \%$ en el tamaño del cuerpo celular.

Por otra parte, en los conteos realizados en la corteza frontal el promedio de células impregnadas en los controles fue de 3,1 por cada $1 \mathrm{~mm}^{2}$, mientras que éste fue considerablemente menor en las muestras infectadas $(1,68-2,15)$. El mayor porcentaje de neuronas que mostraron malformaciones se presentó en el material inoculado con virus 'fijo'.

En el cuadro 1 se resumen los datos correspondientes a las mediciones realizadas con las neuronas impregnadas en las muestras infectadas y sus controles.

\section{Discusión}

La baja proporción de neuronas impregnadas y el hecho particular de que el número de células reveladas en el material infectado haya sido inferior al de los controles no permiten, con estos

Cuadro 1. Datos obtenidos a partir de los cortes de cerebros de diferentes tipos de muestras de ratones infectados con rabia y sus controles procesados mediante la técnica de Golgi. Toda la información sobre neuronas se refiere únicamente a la corteza cerebral y los conteos corresponden a las neuronas encontradas en un área de $1 \mathrm{~mm}^{2}$ de corteza frontal.

\begin{tabular}{|c|c|c|c|c|c|c|c|}
\hline Tipo de muestra & $\begin{array}{l}\text { № de cortes } \\
\text { examinados }\end{array}$ & $\begin{array}{l}\text { № de cortes } \\
\text { con neuronas } \\
\text { impregnadas }\end{array}$ & $\begin{array}{l}\text { * № total de } \\
\text { neuronas } \\
\text { impregnadas }\end{array}$ & $\begin{array}{l}\text { Tamaño del } \\
\text { soma } \\
\text { (área en } \mu \mathrm{m}^{2} \text { ) }\end{array}$ & $\begin{array}{l}{ }^{* *} \text { Promedio } \\
\text { de neuronas } \\
\text { impregnadas en } \\
1 \mathrm{~mm}^{2} \text { de corteza }\end{array}$ & $\begin{array}{c}\text { Neuronas observ } \\
\text { con malformaci } \\
\text { bien marcadas } \\
\text { № }\end{array}$ & $\begin{array}{l}\text { rvadas } \\
\text { ciones } \\
\text { as *** } \\
\%\end{array}$ \\
\hline Controles & 100 & 93 & 289 & 240 & 3,10 & - & - \\
\hline $\begin{array}{l}\text { Inoculación con } \\
\text { virus "calle" por } \\
\text { vía intracerebral }\end{array}$ & 100 & 58 & 108 & 189 & 1,86 & 14 & 12,9 \\
\hline $\begin{array}{l}\text { Inoculación con } \\
\text { virus "calle" por } \\
\text { vía intramuscular }\end{array}$ & 100 & 45 & 97 & 192 & 2,15 & 8 & 8,2 \\
\hline $\begin{array}{l}\text { Inoculación con } \\
\text { virus "fijo" por vía } \\
\text { intramuscular }\end{array}$ & 100 & 41 & 69 & 195 & 1,68 & 22 & 31,8 \\
\hline
\end{tabular}

\footnotetext{
* Suma de neuronas contadas en $1 \mathrm{~mm}^{2}$ de corteza frontal de todos los cortes que contenían, por lo menos, una neurona impregnada.

** Cuociente de la relación: número total de neuronas impregnadas/número de cortes que tenían neuronas impregnadas.

${ }^{* * *}$ Neuronas observadas con malformaciones con relación al número total de neuronas impregnadas
} 
resultados, vislumbrar el alcance de la patología dendrítica en rabia. No obstante, la evidencia aquí presentada es suficiente para afirmar que la rabia sí puede inducir daño neuronal estructural. La morfología característica de las neuronas piramidales (20) fue alterada por la infección.

Sin embargo, la patología dendrítica aquí descrita no es específica para rabia; anormalidades similares se han encontrado en otras enfermedades neurológicas (5,6,21-23). Golgi describió e ilustró con dibujos "diferentes grados de degeneración y atrofia" en cuerpos neuronales y dendritas de células piramidales de la corteza y el hipocampo en conejos inoculados con virus 'fijo' por vía intracerebral (14).

Recientemente, mediante otras técnicas histológicas se observó degeneración parcial en dendritas de las neuronas piramidales del hipocampo en ratones luego de la inoculación intracerebral con una variante de virus 'fijo' CVS24. El mismo virus inoculado en un cultivo primario de neuronas corticales de ratón prenatal, causó degeneración de los procesos celulares y pérdida de expresión de la proteína asociada a microtúbulos (MAP-2) y de la proteína de neurofilamento (NF-200) (24). Sería importante evaluar el efecto de la rabia in vivo sobre estas proteínas del citoesqueleto. En otras enfermedades neurológicas la patología dendrítica hallada con el método de Golgi se ha correlacionado con pérdida de MAP-2 (21-23). Así mismo, alteraciones en las proteínas NF se han asociado con enfermedades neurodegenerativas (25).

Con microscopía electrónica se ha demostrado que cepas patógenas del virus 'fijo' de la rabia, como la CVS utilizada en nuestro trabajo, provocan cambios en la ultraestructura neuronal cuando se inoculan por vía intracerebral; no ocurre lo mismo con las cepas de virus 'calle' o de virus silvestre que circulan en los huéspedes naturales y cuyo único rasgo patognomónico es la formación de las inclusiones citoplasmáticas conocidas como cuerpos de Negri $(2,26,27)$.

Aquí es importante enfatizar que observamos patología dendrítica en cerebros infectados con virus 'fijo' por la ruta intramuscular y también en animales inoculados con virus 'calle' por vía intracerebral o intramuscular; estas condiciones se aproximan más a lo que ocurre en la infección natural. Ahora bien, aunque se sabe que las células piramidales corticales están entre aquéllas que son más frecuentemente infectadas por el virus de la rabia $(2,4,16)$, no podemos asegurar que cada una de las neuronas que manifestaron cambios estructurales estén infectadas o si se hayan afectado de manera indirecta, por ejemplo, por pérdida de sus conexiones con otras neuronas. Para averiguarlo se requiere combinar la técnica de Golgi con microscopía electrónica $(5,9,13,28)$.

Por otra parte, llama la atención que el número de neuronas impregnadas haya sido inferior en los cerebros de los animales infectados comparado con el material control. No se encontró en la literatura revisada alguna observación similar. Es difícil dar una explicación a este fenómeno pues, como afirma Fairén, "es irónico que no se hayan conducido suficientes estudios dirigidos a comprender los mecanismos químicos de la técnica de Golgi" (28). La impregnación es el resultado de la formación de depósitos intracelulares de cromato argéntico producto de la reacción entre el bicromato de potasio y el nitrato de plata (9).

En un estudio sobre la química del método de Golgi-Colonnier se encontró que la impregnación neuronal depende de los niveles de cromo hexavalente $\left(\mathrm{Cr}^{\mathrm{VI}}\right)$ y trivalente $\left(\mathrm{Cr}^{\mathrm{rlI}}\right)$ en el tejido y en la solución de cromación. Los aldehídos reducen el $\mathrm{Cr}^{\mathrm{V}} \mathrm{a}$ a $\mathrm{Cr}^{\prime \prime \prime}$, un proceso que depende del $\mathrm{pH}$ de la solución. El Cr'll establece puentes de unión con las proteínas, un hecho que los autores consideran determinante en el proceso de impregnación (29). Quizá la infección con el virus de la rabia desencadena cambios bioquímicos en el tejido nervioso que podrían interferir con este mecanismo de impregnación.

En conclusión, con la técnica de Golgi-Colonnier hemos demostrado, en el modelo en ratón, que la rabia está en capacidad de modificar notoriamente la citoarquitectura neuronal e inducir la pérdida de espinas dendríticas. Esto puede afectar la integración sináptica y la neurotransmisión $(5,6)$. Se requiere ensayar otras fórmulas de impregnación argéntica, como la versión más 
reciente del método de Golgi-Cox (30), para incrementar la cantidad de neuronas impregnadas, y acudir a métodos que permitan evaluar cuantitativamente las modificaciones de la arborización dendrítica, tales como el método de Sholl, utilizado en estudios recientes (31-33). Lo anterior combinado con el análisis de la expresión de proteínas del citoesqueleto (MAP-2, NF y otras) contribuirán a determinar qué tan importante puede ser la patología dendrítica como componente de la patogénesis de la rabia.

\section{Agradecimientos}

A Jaime Castellanos del Instituto de Virología de la Universidad El Bosque por su colaboración para llevar a cabo la titulación de los virus. El primer autor recibió entrenamiento sobre la técnica de Golgi en el Instituto de Neurociencias de la Universidad "Miguel Hernández", Alicante, España.

\section{Conflicto de intereses}

Ninguno

\section{Financiación}

Instituto Nacional de Salud y Colciencias a través del proyecto 2104-04-11805 y una beca de doctorado para el primer autor.

\section{Referencias}

1. Toro G, Raad J. Rabia. En: Toro G, Hernández CA, Raad J, editores. Instituto Nacional de Salud 19171997: una historia, un compromiso. Bogotá: Instituto Nacional de Salud; 1997. p.309-18.

2. Iwasaki Y, Tobita M. Pathology. En: Jackson AC, Wunner WH, editores. Rabies. San Diego: Academic Press; 2002. p.283-306.

3. Fu ZF, Jackson AC. Neuronal dysfunction and death in rabies virus infection. J Neurovirol. 2005;11:101-6.

4. Tsiang $\mathbf{H}$. Pathophysiology of rabies virus infection of the nervous system. Adv Virus Res. 1993;42:375-412.

5. Braak H, Braak E. Golgi preparations as a tool in neuropathology with particular reference to investigations of the human telencephalic cortex. Prog Neurobiol. 1985;25:93-139.

6. Jagadha V, Becker L. Dendritic pathology: an overview of Golgi studies in man. Can J Neurol Sci. 1989;16:41-50.

7. Scheibel ME, Scheibel AB. The rapid Golgi method. Indian summer or renaissance? En: Nauta WJ, Ebbesson SO, editores. Contemporary research methods in neuroanatomy. New York: Springer-Verlag; 1970. p.1-11.

8. Millhouse OE. The Golgi methods. En: Heimer L, Robards MJ, editores. Neuroanatomical tract-tracing methods 1. New York: Plenum Press; 1981. p.311-44.

9. Fairén $A$, Smith-Fernández $A$, DeDiego $I$. Organización sináptica de neuronas morfológicamente identificadas: el método de Golgi en microscopía electrónica. En: Armengol JA, Miñano FJ, editores. Bases experimentales para el estudio del sistema nervioso. Vol 1. Sevilla: Secretariado de Publicaciones de la Universidad de Sevilla; 1996. p.17-56.

10. Pannese E. The Golgi stain: invention, diffusion and impact on neurosciences. J Hist Neurosci. 1999;8:132-40.

11. Valverde F. Golgi atlas of the postnatal mouse brain. Viena: Springer-Verlag; 1998.

12. Torres-Fernández 0 . La técnica de impregnación argéntica de Golgi. Conmemoración del centenario del Premio Nóbel de Medicina (1906) compartido por Camillo Golgi y Santiago Ramón y Cajal. Biomédica. 2006;26:498-508.

13. Peters A, Palay SL, Webster H. The fine structure of the nervous system. Neurons and their supporting cells. New York: Oxford University Press; 1991.

14. Golgi C. Ueber die pathologische histologie der rabies experimentalis. Berliner Klinische Wochenschrift. 1894; 31:325-31.

15. Páez A, Núñez C, García C, Boshell J. Epidemiología molecular de epizootias de rabia en Colombia, 19942002: evidencia de rabia humana y canina asociada a quirópteros. Biomédica. 2003;23:19-30.

16. Torres-Fernández $\mathbf{O}$, Yepes GE, Gómez JE, Pimienta HJ. Efecto de la infección por el virus de la rabia sobre la expresión de parvoalbúmina, calbindina y calretinina en la corteza cerebral de ratones. Biomédica. 2004;24:63-78.

17. Torres-Fernández $\mathbf{O}$, Yepes GE, Gómez JE, Pimienta HJ. Calbindin distribution in cortical and subcortical brain structures of normal and rabiesinfected mice. Int J Neurosci. 2005;115:1375-82.

18. Sarmiento L, Rodríguez G, de Serna C, Boshell J, Orozco L. Detection of rabies virus antigens in tissue: immunoenzimatic method. Patología. 1999;37:7-10.

19. DeFelipe J, Fairén A. Synaptic connections of an interneuron with axonal arcades in the cat visual cortex. J Neurocytol. 1988;17:313-23.

20. Feldman ML. Morphology of the neocortical pyramidal neuron. En: Peters A, Jones EG, editores. Cerebral cortex. Cellular components of the cerebral cortex. Vol. 1. New York: Plenum Press; 1984. p.123-200.

21. Armstrong DD. Rett syndrome neuropathology review 2000. Brain Dev. 2001;23 (Suppl.1):S72-S6. 
22. Broadbelt K, Byne W, Jones LB. Evidence for a decrease in basilar dendrites of pyramidal cells in schizophrenic medial prefrontal cortex. Schizophr Res. 2002;58:75-81.

23. Montgomery MM, Dean AF, Taffs F, Stott EJ, Lantos PL, Luthert PJ. Progressive dendritic pathology in cynomolgus macaques infected with simian immunodeficiency virus. Neuropathol Appl Neurobiol. 1999;25:11-9.

24. Li XQ, Sarmento L, Fu ZF. Degeneration of neuronal processes after infection with pathogenic, but not attenuated, rabies viruses. J Virol. 2005;79:10063-8.

25. Liu Q, Xie F, Siedlak SL, Nunomura A, Honda K, Moreira PI, et al. Neurofilament proteins in neurodegenerative diseases. Cell Mol Life Sci. 2004;61:3057-75.

26. Miyamoto K, Matsumoto S. Comparative studies between pathogenesis of street and fixed rabies infection. J Exp Med. 1967;125:447-56.

27. Rodríguez G. Microscopía electrónica de la infección viral. Bogotá: Instituto Nacional de Salud; 1983. p.119-39.
28. Fairén A. Pioneering a golden age of cerebral microcircuits: the births of the combined Golgi-electron microscope methods. Neuroscience. 2005;136:607-14.

29. Angulo A, Merchán JA, Molina M. Golgi-Colonnier method: correlation of the degree of chromium reduction and $\mathrm{pH}$ change with quality of staining. $\mathrm{J}$ Histochem Cytochem. 1994;42:393-403.

30. Gibb R, Kolb B. A method for vibratome sectioning of Golgi-Cox stained whole rat brain. J Neurosci Methods. 1998;79:1-4.

31. Cook SC, Wellman CL. Chronic stress alters dendritic morphology in rat medial prefrontal cortex. J Neurobiol. 2004;60:236-48.

32. Martínez-Téllez R, Gómez-Villalobos M de J, Flores G. Alteration in dendritic morphology of cortical neurons in rats with diabetes mellitus induced by streptozotocin. Brain Res. 2005;1048:108-15.

33. Flores G, Alquicer G, Silva-Gómez AB, Zaldivar G, Stewart J, Quirion R, et al. Alterations in dendritic morphology of prefrontal cortical and nucleus accumbens neurons in post-pubertal rats after neonata excitotoxic lesions of the ventral hippocampus. Neuroscience. 2005;133:463-70. 